\title{
Developing a Nomogram for Predicting Risk of Invasive Mechanical Ventilation in Children With Severe Adenovirus Associated Pneumonia
}

\section{Yin Zhang}

Chongqing Medical University Affiliated Children's Hospital

Jilei Lin

Chongqing Medical University Affiliated Children's Hospital

\section{Zhou Fu}

Chongqing Medical University Affiliated Children's Hospital

Jihong Dai (D 466801096@qq.com )

Chongqing Medical University Affiliated Children's Hospital

\section{Research Article}

Keywords: adenovirus, children, invasive mechanical ventilation, severe pneumonia, nomogram

Posted Date: March 13th, 2021

DOI: https://doi.org/10.21203/rs.3.rs-292164/v1

License: (9) This work is licensed under a Creative Commons Attribution 4.0 International License. Read Full License 


\section{Abstract}

Background: The recognition of the development of poor outcomes in children with HAdV infection in early stage of the disease is vital because of high mortality rates. This study aimed to develop and validate a nomogram in predicting risk of IMV in children with SAdVP at the early stage of the disease.

Methods: The retrospective study collected clinical data of hospitalized children with SAdVP in general wards of a 1900-bed teaching hospital in Chongqing, China (2015-2019). The nomogram was built by using the multivariate logistic regression analysis. The performance of the nomogram was assessed by discrimination, calibration and clinical utility.

Results: Two hundred and seven children with SAdVP were included. Age, level of albumin, atelectasis and creatine kinase MB isoenzyme were identified as predictors in the nomogram. The area under the receiver operating characteristic curve of the nomogram was $0.85(95 \% \mathrm{Cl}, 0.78-0.91)$ in the training set and $0.81(95 \% \mathrm{Cl}, 0.69-0.94)$ in the validating set. A good consistency was observed between the predictions and the actual observations, and decision curve analysis showed that the nomogram was clinically useful.

Conclusions: Nomogram to predict the risk of IMV in children with SAdVP in general wards was established and validated. It may be a valuable tool for clinicians to recognize the risk of IMV for children with SAdVP at the early stage of the disease.

\section{Introduction}

Pneumonia is reported as the main cause of death for children under 5 years old ${ }^{1}$. In China, pneumonia is the main cause of hospitalization for children, which brings a heavy burden to society. Human adenovirus (HAdV) plays an important role in the pathogenesis of pediatric pneumonia and accounts for at least 5$10 \%$ of pediatric respiratory tract infections ${ }^{2,3}$. A total of 51 serotypes and over 70 genotypes of HAdV are known so far and are classified into 7 species (species $A$ to $G$ ) on the basis of serology, whole genome sequencing and phylogenomics ${ }^{4,5}$. Although most infections are asymptomatic, mild, or self-limited, specific serotypes are closely associated with low respiratory tract infections, even severe sequelae ${ }^{6-10}$. It has been reported that mortality rates for untreated severe adenovirus associated pneumonia(SAdVP) may exceed $50 \%$ each year ${ }^{5}$, therefore, the recognition of the development of poor outcomes in children with HAdV infection in early stage of the disease is vital.

There are several widely used critical scores which predict the poor prognosis and severe condition of critically ill children such as Pediatric Risk of Mortality III(PRISM III) ${ }^{11}$, Brighton Pediatric Early Warning Score (Brighton PEWS) ${ }^{12,13}$ and Pediatric Critical IIIness Score $(\mathrm{PCIS})^{14}$. Higher scores indicate higher risk of poor prognosis in PRISM III and Brighton PEWS. On the contrary, lower scores in PCIS infers higher risk of poor prognosis. However, the three critical scores were not specific for children with severe pneumonia, 
thus, they may not work accurately in early recognition of the development of poor outcomes in children with SAdVP.

Considering factors above, this study aims to develop and validate a nomogram and evaluate whether it performs better than the three critical scores in predicting risk of invasive mechanical ventilation(IMV) in children with SAdVP at early stage of the disease.

\section{Patients And Methods}

\section{Data source}

This retrospective study was conducted in a 1900-bed teaching hospital in Chongqing, China. Hospitalized children with SAdVP were enrolled retrospectively from January 2015 to October 2019. The study was approved by the ethics committee of Children's hospital of Chongqing Medical University and conducted according to the Declaration of Helsinki guidelines. The requirement of obtaining informed consent was waived due to the retrospective design of the study, and all patients' information was handled anonymously.

\section{Study population}

The inclusion criteria were: 1) children were admitted into general wards and aged between 1 month and 18 years old, 2) met the criteria of severe pneumonia(see Definitions), 3) human adenovirus-polymerase chain reaction test was positive in nasopharyngeal aspirates. The exclusion criteria were any of the following: 1) the outcomes were caused by other diseases but not SAdVP, 2) the guardian refused to continue the treatment or discharged spontaneously before the outcomes occurred, 3 ) the information was seriously absent.

\section{Data extraction}

The data were collected right after the admission to the general wards (clinical symptoms and signs, laboratory values were obtained within 24 hours of admission, and the radiological data were obtained within 48 hours of admission). The collected data included demographic characteristics, clinical presentations, co-infection, underlying conditions, complications, laboratory values, the HAdV load in nasopharyngeal aspirates, and the outcome: need for invasive mechanical ventilation(IMV).

\section{Definitions}

Pneumonia is commonly defined as the presence of fever or acute respiratory symptoms and evidence of parenchymal infiltrates on a chest radiograph ${ }^{15}$. According to British Thoracic Society Standards of Care Committee, indicators of severe pneumonia among children include hypoxemia (arterial oxygen saturation [SaO2] of $92 \%$ or lower), respiration rate greater than 50 breaths per minute for children older than 1 year or 70 breaths per minute for infants, severe difficulty in breathing, nasal flaring, grunting respiration, signs of dehydration, moderate to severe retractions, intermittent apnea, or poor feeding ${ }^{16}$. 
Atelectasis, pulmonary consolidation, pleurisy and emphysema were diagnosed by clinical symptoms, signs, chest ultrasound and/or computed tomography(CT) testing. Congenital heart disease was defined by American Heart Association Statistics Committee and Stroke Statistics Subcommitte ${ }^{17}$. Bronchopulmonary dysplasia was defined by the National Institute of Child Health and Human Development and National Heart, Lung and Blood Institute ${ }^{18}$. Airway structure abnormality was diagnosed by clinical presentations, signs, chest CT scan, accompanied with bronchoscopy.

\section{Statistical analysis}

Continuous variables were compared by using Mann-Whitney $U$ test and were presented as medians with inter-quartile ranges (IQRs) because most of variables were not normally distributed. Categorical variables were analyzed by the $\chi 2$ test or the Fisher's exact test as appropriate and expressed as numbers (n) and percentages (\%).

In this study, we divided included children into training set (about 70\% data) and validating set (about $30 \%$ data) by random sampling in SPSS software. Variables in training set that had a $p$ value less than 0.15 in the univariate logistic analysis were included in the multivariate logistic regression analysis. The factors picked were used to build the multivariable logistic regression model using stepwise forward selection to determine the predictors for risk of IMV. The inclusion criteria for predictors was $p$ value $<$ 0.05. The predictors picked were presented with a nomogram to predict the need for IMV. The accuracy of the nomogram was assessed by the discrimination ability and the calibration plot in validating set. Area under the curve (AUC) of receiver operating characteristic (ROC) was used to evaluate the discrimination ability of the nomogram. Calibration plot was established to validate the model accompanied with the Hosmer-Lemeshow test. In addition, decision curve analysis (DCA) and clinical impact curve (CIC) were performed to evaluate the clinical utility of the nomogram by calculating the net benefits at different threshold probabilities ${ }^{19,20}$. A p value less than 0.05 was considered statistically significant, and all tests were two-sided. All statistical analyses were performed using SPSS 25.0 and R software 3.61.

\section{Results}

\section{Clinical features}

Two hundred and seven children were finally included in our study. According to the inclusion criteria of this study, there were 58 included children requiring IMV, while 149 included children not requiring IMV. Thus, there were 58 cases in IMV group and 149 cases in control group. The flow chart of including patients is shown in Fig. 1.

All included children were admitted to the general wards and no one had severe extrapulmonary complications such as meningitis, pericarditis, endocarditis, osteomyelitis, arthritis, sepsis, hemolytic uremia syndrome, etc. Children were younger in IMV group compared with control group $(p=0.002)$. There were more children complicated by atelectasis in IMV group than control group $(p=0.02)$. Hemoglobin $(\mathrm{Hb})(p=0.006)$ and level of albumin(ALB) $(p<0.001)$ were significantly lower in IMV group than control 
group, while creatine kinase $\mathrm{MB}$ isoenzyme(CK-MB) was significantly higher in IMV group than control group $(p=0.02)$. Score of PRISM III was significant higher in IMV group than control group $(p=0.005)$, while children in IMV group had lower score of PCIS than those in control group $(p<0.001)$.

PRISM III, PEWS and PCIS had an AUC of the probability for IMV of 0.69 ( $95 \% \mathrm{Cl}, 0.62-0.77), 0.53$ (95\% $\mathrm{Cl}, 0.44-0.62)$ and $0.67(95 \% \mathrm{Cl}, 0.58-0.76)$, respectively(Figure S1). The descriptive statistics of all included children are presented in Table 1 . There were 145 children finally divided into training set and 62 into validating set after random sampling. Summarized information in sub-sets is shown in Table S1. 
Table 1

The clinical characteristics between IMV and control groups

$$
\operatorname{Total}(n=207) \quad \begin{array}{ll}
\text { IMV group }(n= & \left.\begin{array}{l}
\text { Control group }(n \\
=149
\end{array}\right)
\end{array} \quad p
$$

\section{Demographic characteristics}

\begin{tabular}{|c|c|c|c|c|}
\hline Age(months) & $\begin{array}{l}12.0(7.0- \\
24.0)\end{array}$ & $8.5(6.0-16.0)$ & $14.0(8.0-26.0)$ & 0.002 \\
\hline Sex[girls(boys),n] & $71(136)$ & $20(38)$ & $51(98)$ & 0.97 \\
\hline Weight(kg) & $9.5(8.0-11.3)$ & $9.00(7.5-11.0)$ & $9.5(8.0-11.5)$ & 0.09 \\
\hline \multicolumn{5}{|l|}{ Clinical presentations, n(\%) } \\
\hline Crackles & $76(36.7 \%)$ & $23(39.7 \%)$ & $53(35.6 \%)$ & 0.58 \\
\hline Length of fever & $5.0(2.0-10.0)$ & $6.0(2.0-11.0)$ & $5.0(2.0-9.0)$ & 0.31 \\
\hline Accompanied with virus infection & $22(10.6 \%)$ & $7(12.1 \%)$ & $15(10.1 \%)$ & 0.68 \\
\hline $\begin{array}{l}\text { Accompanied with bacteria } \\
\text { infection }\end{array}$ & $113(54.6 \%)$ & $33(56.9 \%)$ & $80(53.7 \%)$ & 0.68 \\
\hline $\begin{array}{l}\text { Accompanied with mycoplasma } \\
\text { pneumoniae }\end{array}$ & $35(16.9 \%)$ & $7(12.1 \%)$ & $28(18.8 \%)$ & 0.25 \\
\hline $\begin{array}{l}\text { Length of disease before } \\
\text { admission(days) }\end{array}$ & $\begin{array}{l}12.0(7.0- \\
20.0)\end{array}$ & $11.5(6.0-20.0)$ & $12.0(7.0-20.0)$ & 0.65 \\
\hline \multicolumn{5}{|l|}{ Underlying conditions, n(\%) } \\
\hline Congenital heart disease & $71(34.3 \%)$ & $24(41.4 \%)$ & $47(31.5 \%)$ & 0.18 \\
\hline Moderate-to-severe malnutrition & $5(2.4 \%)$ & $1(1.7 \%)$ & $4(2.7 \%)$ & 1.00 \\
\hline Bronchopulmonary dysplasia & $4(1.9 \%)$ & $1(1.7 \%)$ & $3(2.0 \%)$ & 1.00 \\
\hline Airway structure abnormality & $36(17.4 \%)$ & $10(17.2 \%)$ & $26(17.4 \%)$ & 0.97 \\
\hline \multicolumn{5}{|l|}{ Complications, n(\%) } \\
\hline Atelectasis & $31(15.0 \%)$ & $14(24.1 \%)$ & $17(11.4 \%)$ & 0.02 \\
\hline Pulmonary consolidation & $154(74.4 \%)$ & $47(81.0 \%)$ & 107(71.8\%) & 0.28 \\
\hline Pleurisy & $46(22.2 \%)$ & $17(29.3 \%)$ & $29(19.5 \%)$ & 0.13 \\
\hline $\begin{array}{l}\text { Mediastinal or cutaneous } \\
\text { emphysema }\end{array}$ & $2(1.0 \%)$ & $1(1.7 \%)$ & $1(0.7 \%)$ & 0.48 \\
\hline Gastrointestinal dysfunction & $103(49.8 \%)$ & $31(53.4 \%)$ & $72(48.3 \%)$ & 0.51 \\
\hline \multicolumn{5}{|l|}{ Laboratory values } \\
\hline $\mathrm{WBC}\left({ }^{\star} 10^{\wedge} 9\right)$ & $9.8(6.6-13.4)$ & $10.5(6.6-14.0)$ & $9.6(6.6-13.1)$ & 0.99 \\
\hline
\end{tabular}




\begin{tabular}{|c|c|c|c|c|}
\hline & Total $(n=207)$ & $\begin{array}{l}\text { IMV group }(n= \\
58)\end{array}$ & $\begin{array}{l}\text { Control group (n } \\
=149)\end{array}$ & $p$ \\
\hline L(\%) & $0.4(0.3-0.5)$ & $0.3(0.3-0.5)$ & $0.4(0.2-0.5)$ & 0.31 \\
\hline $\operatorname{PLT}\left(* 10^{\wedge} 9\right)$ & $\begin{array}{l}325.0(249.0- \\
436.0)\end{array}$ & $\begin{array}{l}296.5(234.0- \\
478.0)\end{array}$ & $\begin{array}{l}333.0(253.0- \\
416.0)\end{array}$ & 0.99 \\
\hline $\mathrm{Hb}(\mathrm{g} / \mathrm{L})$ & $\begin{array}{l}\text { 108.0(98.5- } \\
118.0)\end{array}$ & $\begin{array}{l}\text { 103.5(95.0- } \\
116.0)\end{array}$ & $\begin{array}{l}110.0(100.0- \\
121.0)\end{array}$ & 0.006 \\
\hline РСТ(ng/ml) & $0.6(0.1-1.8)$ & $1.2(0.3-2.6)$ & $0.5(0.1-1.5)$ & 0.17 \\
\hline $\mathrm{CRP}(\mathrm{mg} / \mathrm{L})$ & $4.0(4.0-25.5)$ & $11.0(4.0-29.0)$ & $4.0(4.0-24.0)$ & 0.39 \\
\hline $\mathrm{ALT}(\mathrm{U} / \mathrm{L})$ & $\begin{array}{l}26.3(18.6- \\
37.7)\end{array}$ & $\begin{array}{l}30.2(18.4- \\
45.0)\end{array}$ & $25.3(19.1-35.6)$ & 0.14 \\
\hline AST(U/L) & $\begin{array}{l}49.1(38.2- \\
77.5)\end{array}$ & $\begin{array}{l}61.0(42.2- \\
97.1)\end{array}$ & $47.8(37.5-69.0)$ & 0.07 \\
\hline $\mathrm{ALB}(\mathrm{g} / \mathrm{L})$ & $\begin{array}{l}37.2(32.2- \\
41.9)\end{array}$ & $\begin{array}{l}33.0(26.9- \\
37.9)\end{array}$ & $38.0(33.8-43.0)$ & $\begin{array}{l}<.001 \\
0.00\end{array}$ \\
\hline $\mathrm{LDH}(\mathrm{U} / \mathrm{L})$ & $\begin{array}{l}450.0(315.5- \\
674.5)\end{array}$ & $\begin{array}{l}432.3(313.9- \\
858.0)\end{array}$ & $\begin{array}{l}455.0(317.0- \\
647.8)\end{array}$ & 0.10 \\
\hline CK-MB(U/L) & $1.3(0.7-2.8)$ & $2.4(1.2-4.0)$ & $1.0(0.6-2.0)$ & 0.02 \\
\hline HAdV load (InPCR) & $\begin{array}{l}16.2(11.7- \\
18.2)\end{array}$ & $\begin{array}{l}16.3(11.8- \\
17.8)\end{array}$ & $16.2(11.6-18.3)$ & 0.85 \\
\hline \multicolumn{5}{|c|}{$\begin{array}{l}\text { Note: The data were collected right after the admission to the general wards (clinical symptoms and } \\
\text { signs, laboratory values were obtained within } 24 \text { hours, and the radiological data were obtained within } \\
48 \text { hours after admission). No one had severe extrapulmonary complications such as meningitis, } \\
\text { pericarditis, endocarditis, osteomyelitis, arthritis, sepsis, hemolytic uremia syndrome, etc. }\end{array}$} \\
\hline \multicolumn{5}{|c|}{$\begin{array}{l}\text { Abbreviations: ALB, albumin; ALT, alanine aminotransferase; AST, aspartate transaminase; CK-MB, } \\
\text { creatine kinase MB isoenzyme; CRP, C-reactive protein; Hb, hemoglobin; IMV, invasive mechanical } \\
\text { ventilation; L, lymphocyte ratio; LDH, lactic dehydrogenase; In, Napierian logarithm; N, neutrophil ratio; } \\
\text { PCR, polymerase chain reaction; PCT, procalcitonin; PLT, platelet; WBC, white blood cell. }\end{array}$} \\
\hline
\end{tabular}

\section{Developing a predictive nomogram in training set}

In the univariate logistic analysis, eight out of thirty variables were chosen to be included in the multivariate logistic regression analysis. Finally, four predictors were selected for high risk factors for need for IMV in training set including age (odds ratio [OR]: 0.96; 95\% Cl:0.92-0.99; $<<0.05$ ), level of ALB(OR: $0.87 ; 95 \% \mathrm{Cl}: 0.80-0.93 ; p<0.001), \mathrm{CK}-\mathrm{MB}(\mathrm{OR}: 1.32 ; 95 \% \mathrm{Cl}: 1.06-1.80 ; p<0.05)$ and atelectasis(OR: 4.83; 95\% Cl:1.69-14.51; $\mathrm{p}<0.01$ ) (Table 2). 
Table 2

Logistic regression analysis of predictors of IMV in training set

\begin{tabular}{|c|c|c|c|c|}
\hline \multicolumn{3}{|l|}{ Univariate logistic analysis } & \multicolumn{2}{|c|}{$\begin{array}{l}\text { Multivariate logistic } \\
\text { analysis }\end{array}$} \\
\hline Variables & $\mathrm{OR}(95 \% \mathrm{Cl})$ & $\begin{array}{l}\mathrm{p}- \\
\text { value }\end{array}$ & $\mathrm{OR}(95 \% \mathrm{Cl})$ & $\begin{array}{l}\mathrm{p}- \\
\text { value }\end{array}$ \\
\hline Age & $\begin{array}{l}0.95(0.92- \\
0.99)\end{array}$ & 0.005 & $0.96(0.92-0.99)$ & 0.023 \\
\hline Sex & $\begin{array}{l}0.75(0.35- \\
1.59)\end{array}$ & 0.45 & & \\
\hline Weight & $\begin{array}{l}0.88(0.79- \\
0.99)\end{array}$ & 0.03 & & \\
\hline Crackles & $\begin{array}{l}1.28(0.61- \\
2.67)\end{array}$ & 0.17 & & \\
\hline Length of fever & $\begin{array}{l}1.03(0.98- \\
1.09)\end{array}$ & 0.24 & & \\
\hline Accompanied with virus infection & $\begin{array}{l}1.52(0.48- \\
4.86)\end{array}$ & 0.48 & & \\
\hline Accompanied with bacteria infection & $\begin{array}{l}1.00(0.48- \\
2.10)\end{array}$ & 1.00 & & \\
\hline $\begin{array}{l}\text { Accompanied with mycoplasma } \\
\text { pneumoniae }\end{array}$ & $\begin{array}{l}0.74(0.25- \\
2.16)\end{array}$ & 0.58 & & \\
\hline Length of disease before admission & $\begin{array}{l}1.02(0.98- \\
1.05)\end{array}$ & 0.38 & & \\
\hline Congenital heart disease & $\begin{array}{l}1.41(0.67- \\
2.99)\end{array}$ & 0.36 & & \\
\hline Moderate-to-severe malnutrition & $\begin{array}{l}0.87(0.09- \\
8.64)\end{array}$ & 0.91 & & \\
\hline Bronchopulmonary dysplasia & - & - & & \\
\hline Airway structure abnormality & $\begin{array}{l}0.65(0.22- \\
1.87)\end{array}$ & 0.42 & & \\
\hline Pulmonary consolidation & $\begin{array}{l}1.80(0.72- \\
4.52)\end{array}$ & 0.21 & & \\
\hline Atelectasis & $\begin{array}{l}2.68(1.15- \\
6.26)\end{array}$ & 0.02 & $\begin{array}{l}4.83(1.69- \\
14.51)\end{array}$ & 0.004 \\
\hline Pleurisy & $\begin{array}{l}1.56(0.71- \\
3.41)\end{array}$ & 0.27 & & \\
\hline Mediastinal or cutaneous emphysema & $\begin{array}{l}2.67(0.16- \\
43.68)\end{array}$ & 0.49 & & \\
\hline
\end{tabular}




\section{Univariate logistic analysis}

\begin{tabular}{|c|c|c|c|c|}
\hline Gastrointestinal dysfunction & $\begin{array}{l}1.53(0.73- \\
3.20)\end{array}$ & 0.26 & & \\
\hline WBC & $\begin{array}{l}1.01(0.96- \\
1.06)\end{array}$ & 0.79 & & \\
\hline L & $\begin{array}{l}0.63(0.14- \\
2.90)\end{array}$ & 0.55 & & \\
\hline PLT & $\begin{array}{l}1.00(1.00- \\
1.00)\end{array}$ & 0.37 & & \\
\hline $\mathrm{Hb}$ & $0.98(0.95-1.00)$ & 0.05 & & \\
\hline PCT & $\begin{array}{l}1.03(0.99- \\
1.06)\end{array}$ & 0.16 & & \\
\hline CRP & $\begin{array}{l}1.00(0.99- \\
1.01)\end{array}$ & 0.86 & & \\
\hline ALT & $1.01(1.00-1.02)$ & 0.15 & & \\
\hline AST & $1.00(1.00-1.01)$ & 0.09 & & \\
\hline ALB & $\begin{array}{l}0.88(0.82- \\
0.94)\end{array}$ & $<.001$ & $0.87(0.80-0.93)$ & $<.001$ \\
\hline LDH & $\begin{array}{l}1.00(1.00- \\
1.00)\end{array}$ & 0.12 & & \\
\hline CK-MB & $\begin{array}{l}1.45(1.15- \\
1.83)\end{array}$ & 0.002 & $1.32(1.06-1.80)$ & 0.04 \\
\hline InPCR & $\begin{array}{l}1.01(0.93- \\
1.10)\end{array}$ & 0.80 & & \\
\hline \multicolumn{5}{|c|}{$\begin{array}{l}\text { Abbreviations: ALB, albumin; ALT, alanine aminotransferase; AST, aspartate transaminase; CK-MB, } \\
\text { creatine kinase MB isoenzyme; CRP, C-reactive protein; Hb, hemoglobin; ICU, intensive care unit; IMV, } \\
\text { invasive mechanical ventilation; L, Iymphocyte ratio; LDH, lactic dehydrogenase; In,Napierian } \\
\text { logarithm; N, neutrophil ratio; NPA, nasopharyngeal aspirate; PCIS, Pediatric Critical IIIness Score; PCR } \\
\text { polymerase chain reaction of human adenovirus; PEWS, Pediatric Early Warning Score; PCT, } \\
\text { procalcitonin; PLT, platelet; PRISM III, Pediatric Risk of Mortality III; WBC, white blood cell. }\end{array}$} \\
\hline
\end{tabular}

A predictive nomogram incorporating the 4 predictors was established by logistic regression (Fig. 2). The AUC of the probability of IMV for the predictive model was $0.85(95 \% \mathrm{Cl}, 0.78-0.91)$ in training set, which is bigger than the 4 optimal predictors[age: $0.73(95 \% \mathrm{Cl}, 0.63-0.82)$, level of ALB: $0.70(95 \% \mathrm{Cl}, 0.60-$ 0.79), atelectasis: 0.59 (95\% Cl, 0.51-0.67), CK-MB: 0.72 (95\% Cl, 0.62-0.83)] (Figure S2). 
Validation of the predictive nomogram was performed with a 1000-bootstrap analysis. Harrell's concordance index in the validating set was 0.81 . In the validating set, AUC of the probability for IMV was 0.81 (95\% Cl, 0.69-0.94). The calibration curves of the predictive nomogram showed good probability consistencies between the prediction and observation in training set (Fig. 3A) and validating set (Fig. 3B). Hosmer-Lemeshow goodness-of-fit test indicated no significant deviation between observed and predicted events in validating set $(p=0.55)$.

The clinical value of the predictive nomogram was conducted by DCA and CIC analysis. DCA is a novel method for evaluating alternative predictive strategies, which has advantages over the ROC. The DCA curve showed obvious net benefits of the predictive nomogram. The CIC of this predictive model visually showed the estimated number that would be declared as high risk for each risk threshold and the proportion of those who were cases (true positives). The DCA curve and CIC for the predictive model in the validating set is presented in Figure S3.

\section{Comparison with three critical scores}

In validating set, PRISM III, PEWS and PCIS had a AUC of the probability for IMV of $0.72(95 \% \mathrm{Cl}, 0.58-$ $0.85,0.60(95 \% \mathrm{Cl}, 0.43-0.76)$ and $0.58(95 \% \mathrm{Cl}, 0.41-0.75)$, respectively(Fig. 4A). The AUC of the probability for IMV for the predictive model was bigger than all the three scales. Significant difference was obtained in PEWS, PCIS and PRISM III (all p < 0.05) in comparison with the new predictive model, respectively. The DCA curves showed the predictive nomogram had more obvious net benefits than the three critical scores(Fig. 4B).

\section{Discussion}

In this study, we established a simple-to-use nomogram-illustrated model to predict the risk of IMV in children with SAdVP in general wards at admission. The predictive nomogram incorporated 4 predictors including age, ALB, CK-MB and atelectasis. The nomogram showed good accuracy and discrimination, which indicated that the nomogram may have a good utility in clinical practice. The significant difference in AUC suggested the new predictive model performs better than three critical scores including PRISM III, PEWS and PCIS in predicting the need for IMV.

Early recognition of the prognosis in children with SAdVP may help physicians to adopt effective therapies in early stage to prevent the deterioration of disease. Previous studies have reported that younger age, lower ALB and obvious complications were risk factors for the deterioration of disease in children with adenovirus infection ${ }^{21}$. The results of this study also showed that younger age was the independent risk factor in early stage. To our knowledge, there was no significantly effective medicine for adenovirus infection, thus prognosis usually depends on the immune system of patients. Younger children usually have immature immunity and limited respiratory function. There are some specific biomarkers for evaluating the severity of bacterial infection, such as CRP and $\mathrm{PCT}^{22}$, while no specific biomarkers have been yet found in pediatric virus infection. Therefore, we evaluated the value of 
biomarkers in children with SAdVP based on available laboratory indexes. ALB is regarded as a kind of negative acute-phase protein and a marker of inflammation which is often decreased in the inflammatory process $^{23}$. One study suggested low serum ALB levels at admission may be risk factors of mortality for patients with viral pneumonia ${ }^{24}$. The result of our study was consistent with the study, showing that lower ALB might be a predictor for requiring IMV at early stage of SAdVP. Besides, CK-MB is one of the major specific serum cardiac markers and elevated CK-MB is often observed in myocardial ischemic and hypoxic change. One previous study showed CK-MB was found to be high in all included pediatric patients with pneumonia who had poor prognosis ${ }^{25}$. Similarly, our study suggested that the increasing CK-MB was a risk factor for IMV in children with SAdVP. We suppose that the inflammation of lung may increase the burden of blood circulation in the heart. Atelectasis usually indicates the lung involvement of infection. The results of this study showed that the length of disease before admission was not significant different between two groups, but the incidence of atelectasis was obviously higher in IMV group. Hence, atelectasis may herald the rapid development of disease, and the earlier occurrence may indicate poor prognosis.

The strengths of this study are highlighted. To our knowledge, this is the first study to establish a nomogram to predict the risk of IMV in children with SAdVP at early stage. And the predictive model showed good discrimination and consistency ability. The nomogram can be used in early recognition of SAdVP cases with high risk of poor outcomes, thus timely treatment and care should be provided to these children. Also, the results showed the new predictive model performed better than three critical scores(not only PRISM III and PEWS which are worldwide used, but also PCIS, specially formulated for Chinese children).

The weak points of this study should be noted as well. AUC of the predictive model was not high enough, which could be explained by the lack of specificity in pediatric virus infection. Also, this study had a small sample size. Prospective researches with large sample size are needed to validate and improve the predictive model. Furthermore, the data of this study were not obtained in the same time because this is a retrospective study. It may lead the bias of the predictive model.

The findings of this study may have implications for clinical practice. First, younger age, lower level of ALB, increase of CK-MB and atelectasis may indicate higher risk of IMV in children with SAdVP. Second, we should value the status of patients through synthetical analysis since combination of these predictors performed better than single predictors. Third, the commonly used critical scores did not perform well in predicting the risk of IMV for children with SAdVP, therefore, the first predictive model for them is necessary.

\section{Conclusions}

In conclusion, we established and validated a nomogram to predict the risk of invasive mechanical ventilation in children with severe adenovirus associated pneumonia at early stage of the disease. The nomogram has a more adequate ability of discrimination, calibration than PRISM III, PEWS and PCIS. It

Page $11 / 19$ 
may be a valuable tool for clinicians to recognize the risk of invasive mechanical ventilation for children with severe adenovirus associated pneumonia at early stage.

\section{Declarations}

\section{Ethics approval and consent to participate:}

The requirement for individual patient consent was waived because the project did not impact clinical care, and all protected health information was deidentifed.

\section{Consent for publication:}

Not applicable.

\section{Availability of data and materials:}

All data generated or analysed during this study are included in this published article and the supplementary information files.

\section{Conflict of interest statement:}

The authors declare that they have no conflict of interest.

\section{Funding:}

None

\section{Authors' contributions:}

Yin Zhang conceptualized and designed the study, supervised data collection, carried out the initial analyses, drafted the initial manuscript. Jilei Lin designed the data collection instruments, collected data. Yin Zhang and Jilei Lin coordinated and supervised data collection, assisted in the statistical analysis and carried out the initial analyses. Zhou Fu coordinated and supervised data collection, and critically reviewed the manuscript for important intellectual content. Jihong Dai conceptualized and designed the study, supervised data collection, reviewed and revised the manuscript. All authors read and approved the final manuscript.

\section{Acknowledgements:}

Not applicable.

\section{References}

1. UNICEF. Levels \& Trends in Child Mortality Report 2017 Estimates Developed by the UN Inter-agency Group for Child Mortality Estimation. United Nations Children's Fund.2017. 
2. Ning $G$, Wang $X, W u D$, et al. The etiology of community-acquired pneumonia among children under 5 years of age in mainland China, 2001-2015: A systematic review. Hum Vaccin Immunother.2017;13:2742-2750.

3. Lee J, Choi EH, Lee HJ. Comprehensive serotyping and epidemiology of human adenovirus isolated from the respiratory tract of Korean children over 17 consecutive years (1991-2007). J Med Virol. 2010:82:624-631.

4. Hage E, Gerd Liebert U, Bergs S, Ganzenmueller T, Heim A. Human mastadenovirus type 70: a novel, multiple recombinant species $D$ mastadenovirus isolated from diarrhoeal faeces of a haematopoietic stem cell transplantation recipient. J Gen Virol. 2015;96:2734-2742.

5. Lynch JP 3rd, Kajon AE. Adenovirus: Epidemiology, Global Spread of Novel Serotypes, and Advances in Treatment and Prevention. Semin Respir Crit Care Med. 2016;37:586-602.

6. Chau SK, Lee SL, Peiris MJ, et al. Adenovirus respiratory infection in hospitalized children in Hong Kong: serotype-clinical syndrome association and risk factors for lower respiratory tract infection. Eur J Pediatr. 2014;173:291-301.

7. Hong JY, Lee HJ, Piedra PA, et al. Lower respiratory tract infections due to adenovirus in hospitalized Korean children: epidemiology, clinical features, and prognosis. Clin Infect Dis. 2001;32:1423-1429.

8. Callaway Z, Kim SH, Kim JY, Kim DW, Kim CK. Adenovirus infection with serious pulmonary sequelae in Korean children. Clin Respir J. 2011;5:92-98.

9. Wo Y, Lu QB, Huang DD, et al. Epidemical features of HAdV-3 and HAdV-7 in pediatric pneumonia in Chongqing, China. Arch Virol. 2015;160:633-638.

10. Li QG, Zheng QJ, Liu YH, Wadell G. Molecular epidemiology of adenovirus types 3 and 7 isolated from children with pneumonia in Beijing. J Med Virol. 1996;49:170-177.

11. Pollack MM, Patel KM, Ruttimann UE. PRISM III: an updated Pediatric Risk of Mortality score. Crit Care Med. 1996;24(5):743-752.

12. Agulnik A, Méndez Aceituno A, Mora Robles LN, et al. Validation of a pediatric early warning system for hospitalized pediatric oncology patients in a resource-limited setting. Cancer. 2017;123(24):4903-4913.

13. Miranda JOF, Camargo CL, Nascimento CL Sobrinho, Portela DS, Monaghan A. Accuracy of a pediatric early warning score in the recognition of clinical deterioration. Rev Lat Am Enfermagem. 2017;25:e2912.

14. Ren XX, Song GW.Pediatric Risk of Mortality III Score and Pediatric Critical IIIness Score. App/ Clin Pediatr. 2006;21(6):382-384.[Chinese]

15. Mclntosh K. Community-acquired pneumonia in children. N Engl J Med. 2002;346:429-437.

16. British Thoracic Society Standards of Care Committee. British Thoracic Society Guidelines for the Management of Community Acquired Pneumonia in Childhood. Thorax. 2002;57(suppl 1):i1-i24.

17. Go AS, Mozaffarian D, Roger VL, et al; American Heart Association Statistics Committee and Stroke Statistics Subcommittee. Heart disease and stroke statistics-2013 update: a report from the 
American Heart Association. Circulation 2013;127(01):e6-e245

18. Jobe AH, Bancalari E. Bronchopulmonary dysplasia. Am J Respir Crit Care Med. 2001;163(7):17231729.

19. Vickers AJ, Elkin EB. Decision curve analysis: a novel method for evaluating prediction models. Med Decis Making. 2006;26:565-574.

20. Fitzgerald M, Saville BR, Lewis RJ. Decision curve analysis. JAMA.2015;313:409-410.

21. Rajkumar V, Chiang CS, Low JM, et al. Risk Factors for Severe Adenovirus Infection in Children during an Outbreak in Singapore. Ann Acad Med Singapore.2015;44:50-59;

22. Amaro R, Liapikou A, Cilloniz C, et al. Predictive and prognostic factors in patients with blood-culturepositive community-acquired pneumococcal pneumonia. Eur Respir J. 2016;48(3):797-807.

23. Kaysen GA, Dubin JA, HEMO Study Group NIDDK, et al. Inflammation and reduced albumin synthesis associated with stable decline in serum albumin in hemodialysis patients. Kidney Int. 2004;65:14081415.

24. Ediboğlu Ö, Ataman S, Kirakli C. Characteristics of influenza pneumonia patients admitted to the ICU due to hypoxemic respiratory failure. Tuberk Toraks. 2018;66:52-56.

25. Ilten F, Senocak F, Zorlu P, Teziç T. Cardiovascular changes in children with pneumonia. Turk J Pediatr. 2003;45(4):306-310.

\section{Figures}




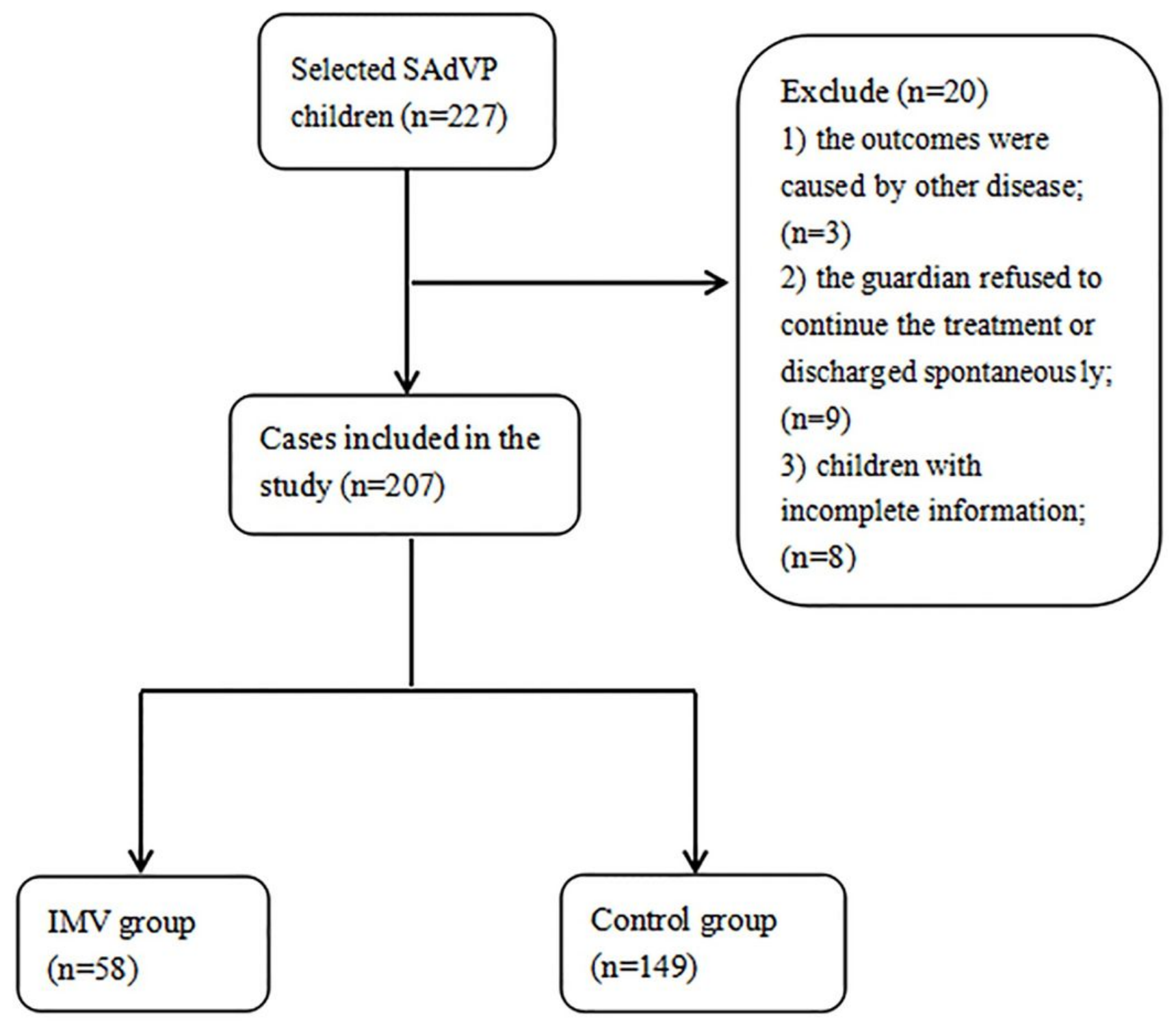

Figure 1

Flow diagram of the population. 


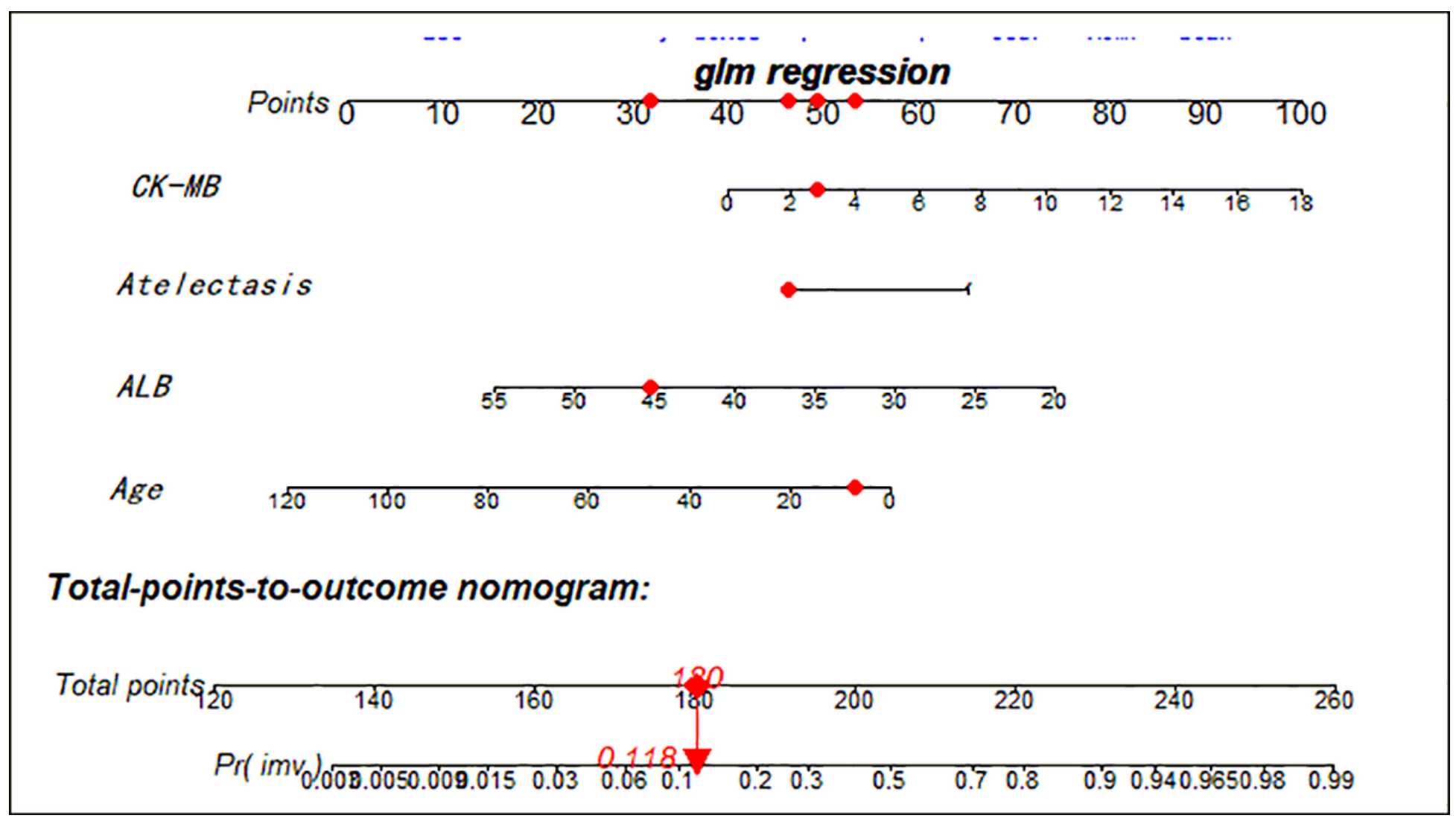

Figure 2

The nomogram established for predicting risk of IMV in training set. 
A

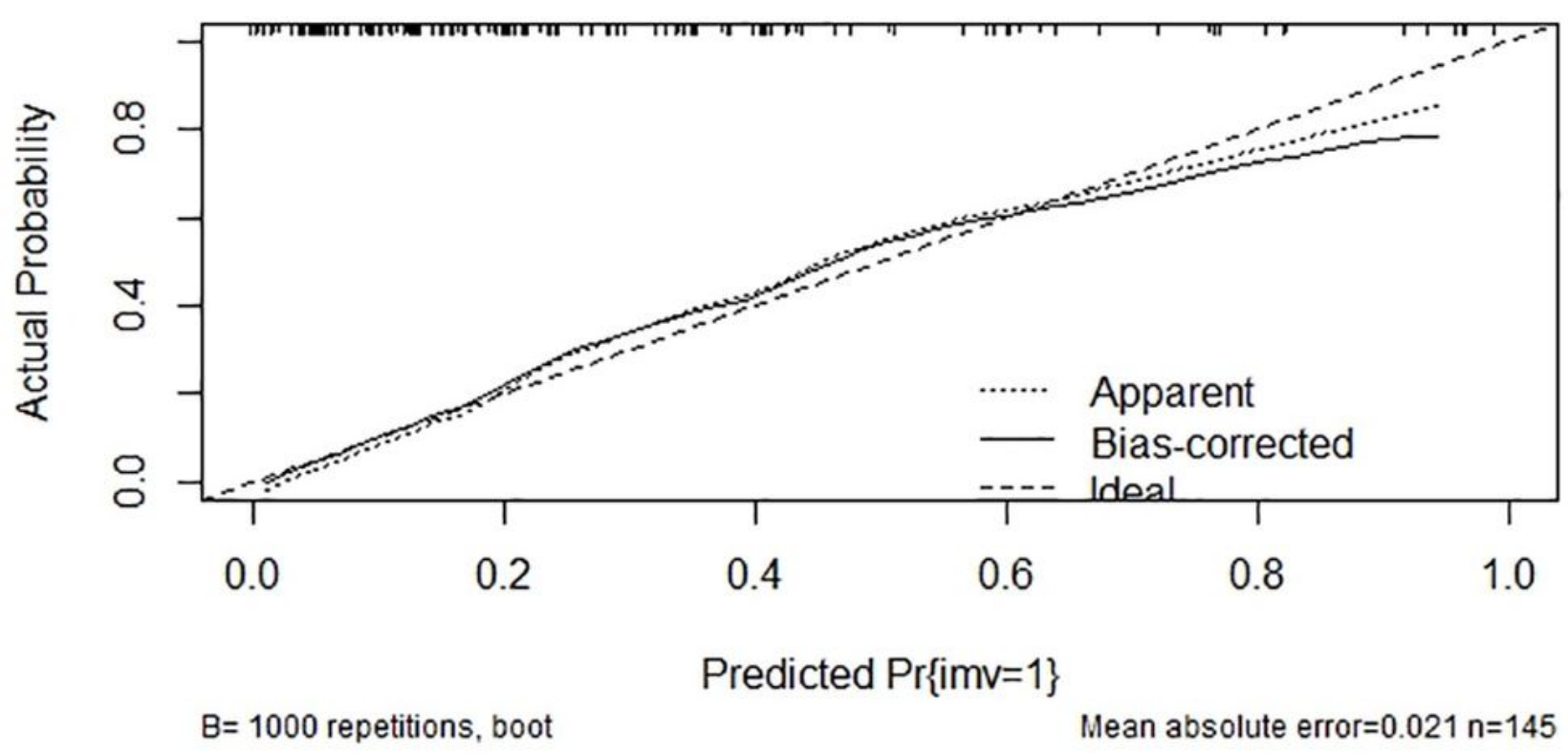

B

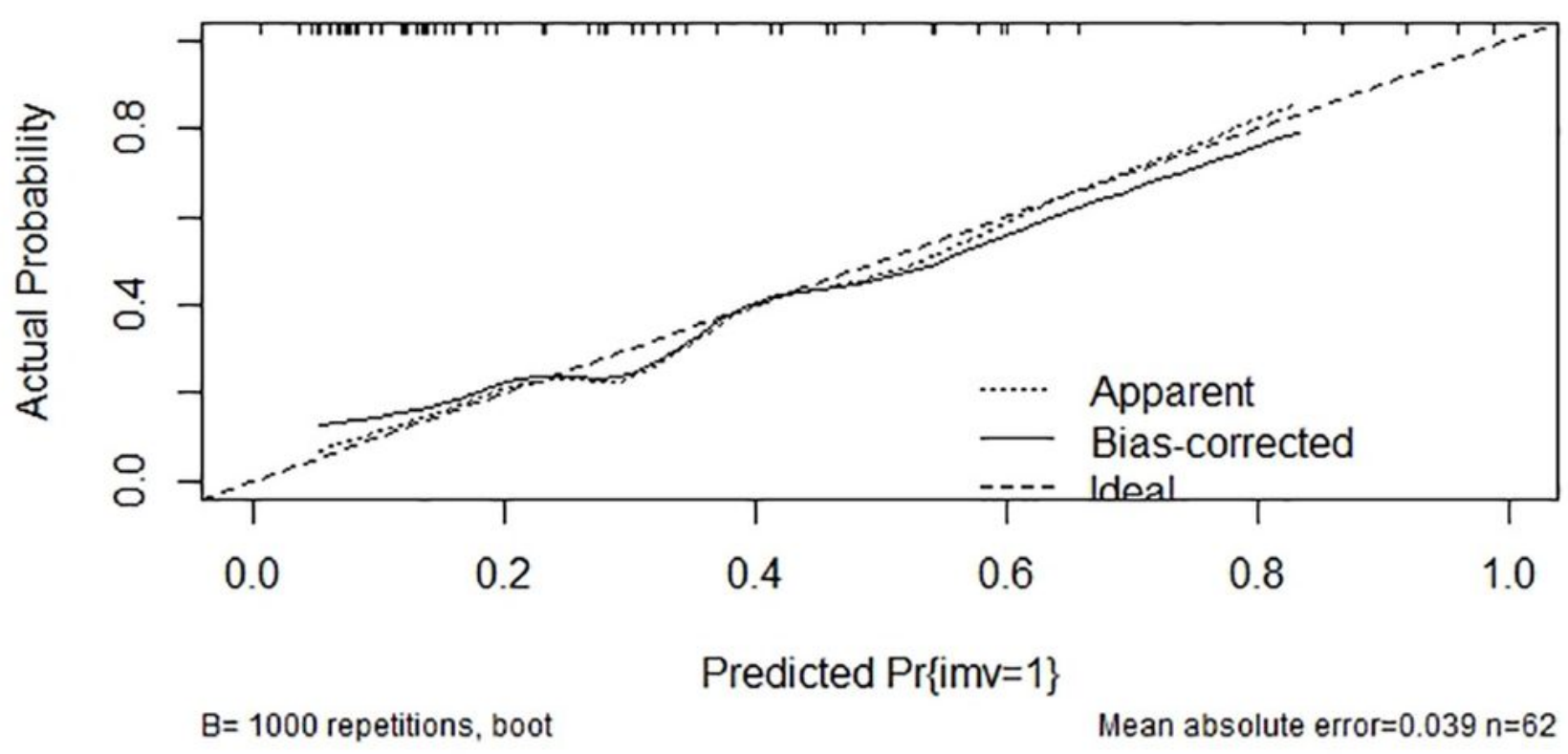

Figure 3

A) Calibration curve for the nomogram in training set. B) Calibration curve for the nomogram in validating set. 


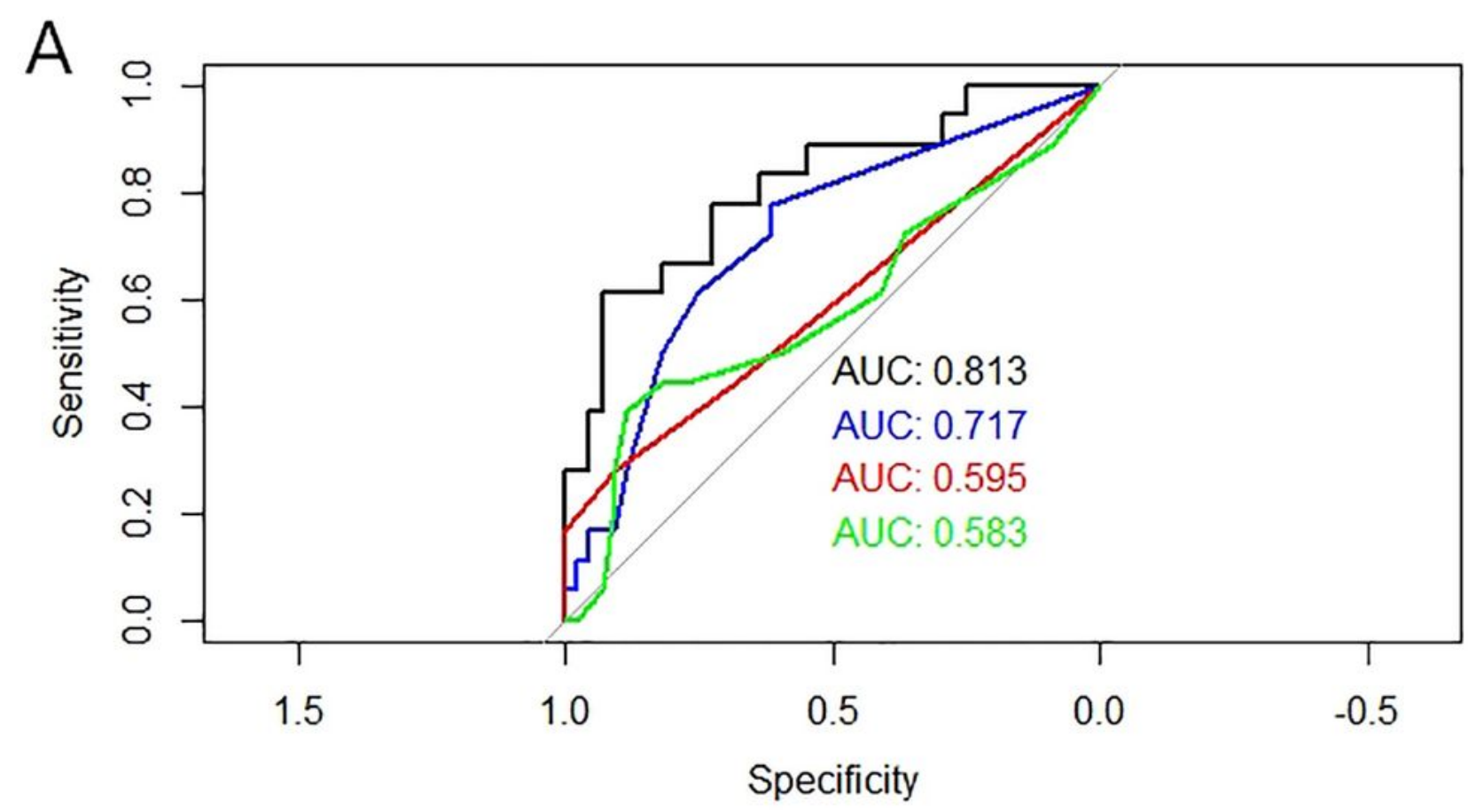

B

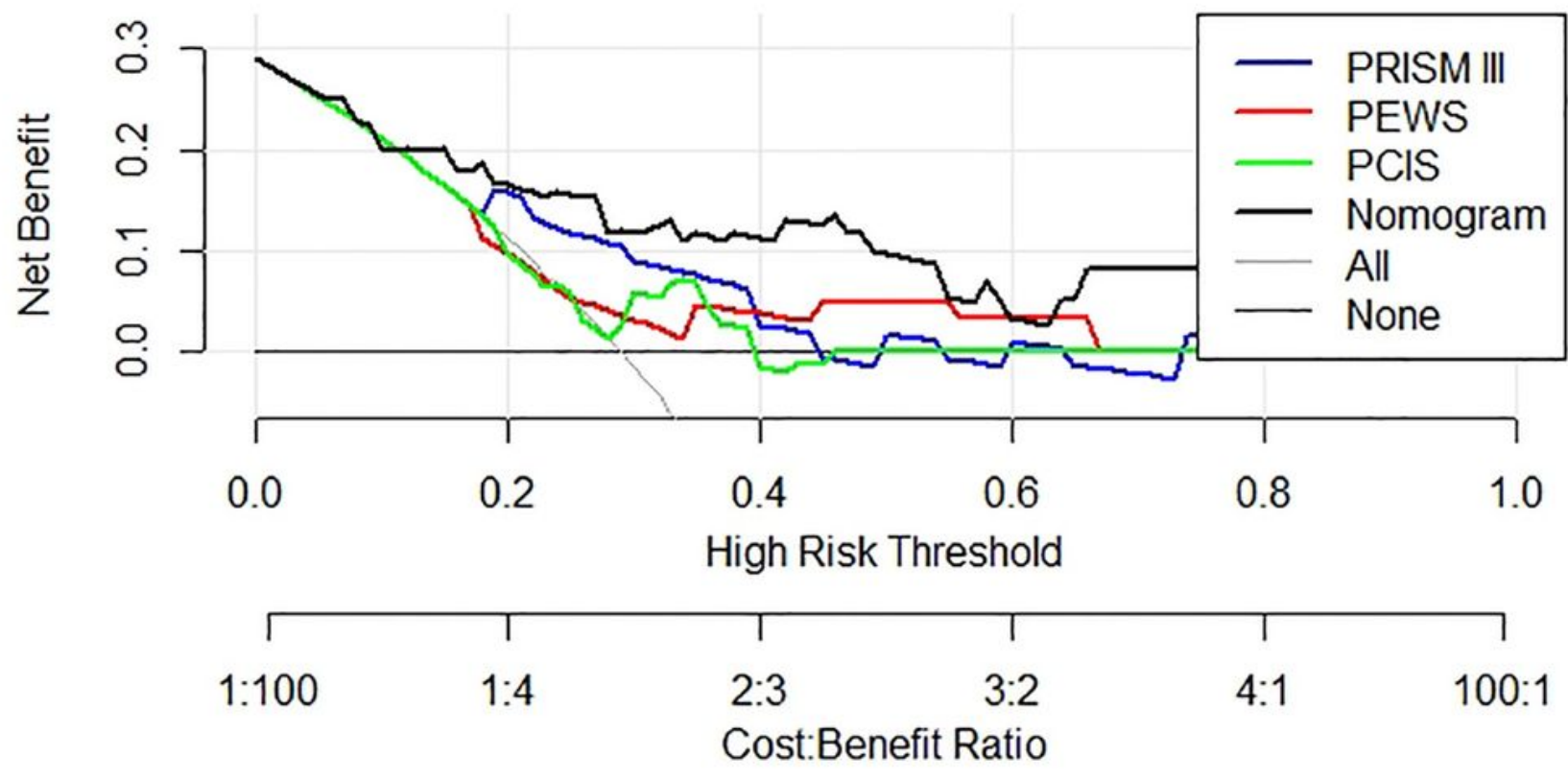

Figure 4

Comparison of the nomogram and the three critical scores in validating set. A) ROC; B) DCA.

\section{Supplementary Files}

This is a list of supplementary files associated with this preprint. Click to download. 
- supplementalmaterial.docx

Page 19/19 